\title{
Development of the Diabetes Oral Health Assessment Tool (C) for Nurses
}

\author{
Yumi Kuwamura1, Masuko Sumikawa2, Tetsuya Tanioka1, Toshihiko Nagata3, \\ Eijiro Sakamoto $^{3}$, Hiromi Murata ${ }^{4}$, Munehide Matsuhisa ${ }^{5}$, Ken-ichi Aihara ${ }^{6}$, \\ Daisuke Hinode ${ }^{7}$, Hirokazu Uemura ${ }^{8}$, Hirokazu Ito', Yuko Yasuhara1, Rozzano Locsin' \\ ${ }^{1}$ Department of Nursing, Institute of Biomedical Sciences, Tokushima University Graduate School, Tokushima, \\ Japan \\ ${ }^{2}$ Sapporo Medical University School of Health Sciences, Hokkaido, Japan \\ ${ }^{3}$ Department of Periodontology and Endodontology, Institute of Biomedical Sciences, Tokushima University \\ Graduate School, Tokushima, Japan \\ ${ }^{4}$ Former Tokushima University Hospital, Tokushima, Japan \\ ${ }^{5}$ Diabetes Therapeutics and Research Center, Tokushima University, Tokushima, Japan \\ ${ }^{6}$ Department of Community Medicine for Diabetes and Metabolic Disorders, Institute of Biomedical Sciences, \\ Tokushima University Graduate School, Tokushima, Japan \\ ${ }^{7}$ Department of Hygiene and Oral Health Science, Institute of Biomedical Sciences, Tokushima University \\ Graduate School, Tokushima, Japan \\ ${ }^{8}$ Department of Preventive Medicine, Institute of Biomedical Sciences, Tokushima University Graduate School, \\ Tokushima, Japan \\ Email: kuwamura.yumi@tokushima-u.ac.jp
}

Received 22 November 2015; accepted 25 December 2015; published 28 December 2015

Copyright (C) 2015 by authors and Scientific Research Publishing Inc.

This work is licensed under the Creative Commons Attribution International License (CC BY). http://creativecommons.org/licenses/by/4.0/

(c) (i) Open Access

\begin{abstract}
Although some studies have suggested a bidirectional relationship between diabetes and periodontal disease, there were no appropriate tools for nurses to evaluate oral status and oral health behaviors in patients with diabetes. Therefore, the Diabetes Oral Health Assessment Tool (DiOHAT(C) was developed with items contributed by health care professionals (diabetologists, periodontal specialists, a preventive dentist, a Certified Nurse in Diabetes Nursing, a national registered dietitian, registered nurses, a dental hygienist, and nursing researchers) who were involved in the medical care of patients with diabetes. Subsequently, a survey of 700 Diabetes Nurse Specialists (DNS) was conducted to determine their score of recognition and implementation of the DiOHAT ${ }^{\complement}$, however, 304 participants $(43.4 \%)$ responded. Constructive concept validation and the Cronbach's alpha coefficient for all assessment items was 0.932 , indicating high reliability: Factor 1 , Patient's oral health status $(\alpha=0.874)$; Factor 2 , Implementation of oral health behaviors $(\alpha=$ 0.890); Factor 3, Information transmission regarding dental visits $(\alpha=0.862)$; and Factor 4 , Perceptions and knowledge of oral health behaviors $(\alpha=0.793)$. Although the mean score of recognition of DiOHAT@ was $3.5 \pm 0.4$ points, the mean value of the implementation score was $1.5 \pm 0.5$
\end{abstract}


points (obtained using a 4-grade scale). The implementation scores were significantly lower than the recognition scores for all items $(p<0.001)$. The findings suggested that the DNS were not inclined to implement all items of DiOHAT $@$, despite recognizing their importance.

\title{
Keywords
}

\author{
Diabetes, Oral Health Behavior, Oral Status, Nursing Assessment, Diabetes Nurse Specialist
}

\section{Introduction}

It is becoming increasingly important worldwide to take critical measures to manage diabetes. In Japan, there are no signs of a decreasing prevalence of diabetes [1]. The continuing goal of treatment is to prevent or delay complications [2], which can be achieved via patients with diabetes (hereafter referred to as patients) self-care interventions. Patients need not only amend their diet, exercise, and medication but also consider how they can maintain their overall health. Diet therapy is a requirement for all patients. There have been many studies about the relationship between postprandial blood glucose levels and mastication [3]-[5]; eating vegetables before carbohydrate [6]; and higher masticatory performance and slow eating [7]. To implement these behavioral activities, patients need good oral health. The 2011 Survey of Dental Diseases [8] conducted in Japan showed that the percentages of those with the highest community periodontal index codes in permanent teeth were $74.2 \%$ (in total) and $86.7 \%$ (within the age group of 45 - 49 years old). In particular, patients are often susceptible to periodontal disease [9], which can be easily exacerbated [10] by oral health disease conditions. Periodontal disease is referred to as the sixth complication of diabetes [11] and its exacerbation has a negative influence on diabetes [12] [13]. It is therefore important that patients maintain good oral health behaviors to prevent periodontal disease from developing or if existing, from worsening.

In Japan, some attempts have been made to share patient information among medical staffs (e.g., internists, ophthalmologists, and dentists), who treat patients with diabetes by utilizing a diabetes information sharing notebook [14] [15]. Patients bring these notebooks to the medical staffs to report their physical conditions (e.g., hemoglobin A1c levels, retinopathy stage, periodontal disease stage). These surveys by a cooperative medical and dental team also clarified the association between periodontal disease and glycemic control [16].

In a study by nurses aimed to determine support of patients with difficulty maintaining good oral health, in addition to identifying the oral health behaviors and associated factors of the patients [17], the result indicated that it was important for nurses to understand both the perceptions [18] [19] and behaviors of their patients. To prevent severe diabetic complications, such as ischemic heart disease, the goal of oral health behaviors is to prevent the onset and/or worsening of oral diseases, including periodontal disease and dental caries, and their associated diseases [20]. It is also effective to ensure that patients receive appropriate dental care considering their current diabetic therapies.

Clarification of nurses' assessments of patient oral health behaviors will facilitate the provision of support to patients to conduct appropriate oral health behavioral assessments. Current oral health care assessments by Eilers' Oral Assessment Guide [21] and its revised versions [22]-[24] are often used as references. These are assessment methods for the oral cavity, especially for detecting mucositis in patients undergoing chemotherapy [25]-[27] or radiotherapy [28]. However, for nurses' use, there are no existing guidelines for assessing oral status and oral health behaviors of patients that consider diabetes treatment goals and current oral physical status.

The aims of this study were to develop the Diabetes Oral Health Assessment Tool (DiOHATC) which enabled nurses to evaluate patients' oral status and oral health behaviors easily and simply, and to clarify how diabetes nurse specialists recognize the contents of DiOHAT $\odot$ and the frequency of its use in the real world.

\section{Methods}

\subsection{The Process to Develop the Diabetes Oral Health Assessment Tool (DiOHATC) for Nurses}

2.1.1. Identification of Items to Develop the DiOHAT (

From the literature reviews and preliminary survey interviews conducted, sources of items describing the oral 
health status and oral health behaviors were identified to initiate the development of the DiOHAT@. Information derived from interviews with internists, dentists, and nurses who were working in medical or dental departments regarding patients' oral health status and oral health behaviors, were analyzed. From these sources, the draft DiOHAT@ was developed.

\subsubsection{Discussions among Interdisciplinary Team of Professionals}

Discussions among members of the interdisciplinary team of professionals focused on determining the validity of the assessment items of the DiOHAT( . In a meeting conducted by health care professionals (including diabetologists, periodontal specialists, a preventive dentist, a Certified Nurse in Diabetes Nursing, a national registered dietitian, registered nurses, a dental hygienist, and nursing researchers), interdisciplinary approaches to support oral health behaviors for patients, and recognition of effective assessment ways were discussed. From this meeting, the assessment items were identified including terms depicting situations that predict periodontal disease and characteristics of diabetes treatments. Consequently, the draft of the assessment items was modified such that it would be possible for any nurses to easily conduct an efficient bedside assessment. There were more than 50 items in the initial assessment tool. However, after careful discussion and focused consideration, the final assessment items of the DiOHAT( ${ }^{2}$ were reduced to 21, comprising four assessment areas of concern, namely, "Patient's oral health status", "Patient's implementation of oral health behaviors", "Patient's visit to dental clinic", and "Patient's perceptions and knowledge of oral health behaviors".

\subsubsection{Detailed Description of the Assessment Items}

The items included in the area of "Patient's oral health status" are related to the main functions of the teeth and the oral cavity. These are basic items intended to assess mastication and swallowing, vocalization and pronunciation, facial appearance, and saliva secretion.

The items pertaining to "Patient's implementation of oral health behaviors" focused on whether patients are able to perform two critical actions for oral health by themselves: cleaning dental plaque (biofilms) from the surface of teeth (oral self-care), undergoing regular dental examinations and cleanings performed by dentists or dental hygienists (professional oral health care) for the prevention of cavities and periodontal disease.

The items pertaining to "Patient's visit to dental clinic" assessed whether or not patients are able to visit dentists and offer information regarding their therapies from the internists to dentists, and to relay that information to their medical staffs. The common complications of diabetes are incomplete healing of wounds [29] due to hyperglycemia associated with the onset and exacerbation of infectious disease and hypoglycemia caused by delayed or missed meals after the dental therapy, for example during interventions involving the use of anesthesia. In addition, when patients are given an anti-platelet agent, it is often difficult for bleeding to stop. It is also crucial that patients inform their dentists before therapy if they have any diabetes-related complications, such as hypertension and heart disease.

The items pertaining to "Patient's perceptions and knowledge of oral health behaviors" assessed how well the patients understand the close link between periodontal disease and diabetes, and the importance of oral health behaviors.

\subsection{Diabetes Nurse Specialists' Recognition and Implementation of the Diabetes Oral Health Assessment Tool (DiOHAT C)}

\subsubsection{Participants of the Study}

Three hundred four Certified Nurses in Diabetes Nursing and Certified Nurse Specialists in Chronic Care Nursing were recognized as Diabetes Nurse Specialists (DNS) in Japan. Seven-hundred self-administered questionnaires by anonymous form were mailed to the DNS. They agreed to participate in the survey and returned the questionnaires containing the demographic data sheet and the DiOHAT@. The data were collected from December 2014 to January 2015.

\subsubsection{Instruments}

In the questionnaire participants were asked to include their personal data such as age, gender, years of experience as a nurse, certifications as DNS, years passed since the acquisition of certifications, and presence or absence of a specialty outpatient department for diabetes in the clinics where they work.

A five-point Likert scale questionnaire was used with responses for each of the items of the DiOHAT@. 
These items were focused on the necessity of patients' oral health behaviors. Recognition scores were set as follows: "not necessary at all, one point", "not very necessary, two points", "cannot determine, three points", "a little necessary, four points", and "very necessary, five points". Participants were asked to answer the frequency of implementation of the assessment within the last two weeks, by choosing one of four alternatives. Implementation scores were set as follows: "never, one point", "sometimes, two points", "often, three points", and "always, four points". It was found that the higher the score, the more the participants implemented and recognized the necessity of the assessment.

\subsubsection{Methods of Analysis}

The Kaiser-Meyer-Olkin (KMO) measures of sampling adequacy for the factor analysis of the 21 items were calculated, and confirmed an appropriate value of 0.923. In addition, Bartlett's test of sphericity was used to confirm the validation of the factor analysis (chi-squared test value of 3702.6, $p<0.001$ ). The factor analysis was conducted by adopting the principal factor analysis. Regarding the rotation method, the varimax rotation method supplemented with Kaiser Normalization test was used. The analysis was conducted by setting the four factors with the corresponding factor loadings of greater than 0.30 being adopted.

To compare the scores obtained for the recognition of the necessity of each assessment item (five-point scale) and those for implementation of the item (four-point scale), the modified scores for the recognition of necessity were obtained by multiplying these scores by 0.8 . These scores were divided by the number of factors to obtain an average score, which was taken as the score for each factor. In order to compare the recognition and implementation of each assessment item, these were compared using paired t-test. The significance level was set at 5\%. The IBM SPSS Statistics 19.0, 23.0 were used for the statistical analyses.

\subsection{Ethical Considerations}

This research was conducted with the approval of the clinical research ethics review board at Tokushima University Hospital Clinical Trial Center for Developmental Therapeutics (reference number 2042). The approval document states that cooperation with this research is on a voluntary basis, where completing the questionnaire is considered as approval, and cancellation of a response is not permitted because all responses are anonymous. Information for distribution of the questionnaires was obtained from the website of the Japan Nursing Association.

\section{Results}

\subsection{Demographic Data (Table 1)}

Out of the 700 questionnaire copies distributed to prospective participants, only 304 were returned and received. The return rate was $43.4 \%$. The mean age of the participants was $41.7 \pm 6.6$ years. Most of them (74.7\%) worked at the clinic/hospital with a specialty outpatient clinic for patients with diabetes. Although there were 277 Certified Nurses in Diabetes Nursing (CNDN), only 262 responded about the years of work after acquiring their certification. There were 29 Certified Nurse Specialists in Chronic Care Nursing (CNSCCN), but only 24 provided information about years or practice after acquisition of certification.

\subsection{Factor Analysis of the (CDiabetes Oral Health Assessment Tool (Table 2)}

Cronbach's alpha coefficient was 0.932 , showing a high degree of reliability. As a result of the factor analysis, the following classifications were confirmed for the assessment items: Factor 1, Patient's oral health status ( $\alpha=$ 0.874), seven items; Factor 2, Patient's implementation of oral health behaviors $(\alpha=0.890)$, six items; Factor 3 , Patient's information transmission regarding dental visits $(\alpha=0.862)$, five items; and Factor 4, Patient's perceptions and knowledge of oral health behaviors $(\alpha=0.793)$, three items. Additionally, the researchers further considered the following points: whether the assessment items were easy to use and whether the content regarding professional oral health care was adequate.

\subsection{Differences between Diabetes Nurse Specialists' Recognition and Implementation to Assess Patients' Oral Health Status and Behaviors (Table 3)}

The average score for all items pertaining to recognition was $3.5 \pm 0.4$ points out of a possible 4 . In particular, 
Table 1. Characteristics of participants.

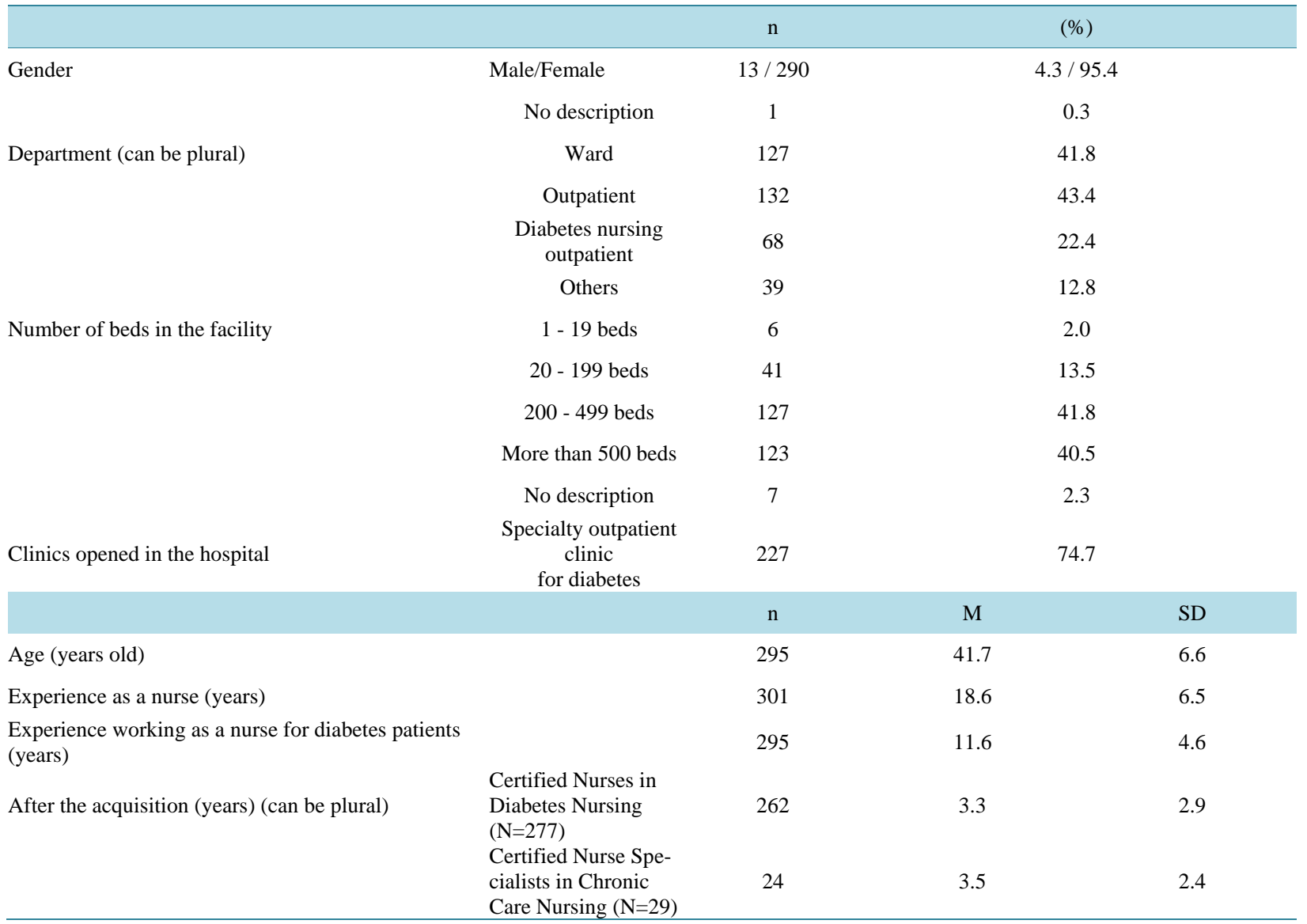

$\mathrm{N}=$ 304, M: Mean, SD: Standard Deviation.

the items regarding "knowledge of a relationship between periodontal disease and systemic disease including diabetes (3.8 \pm 0.4$)$ " and "dental visiting more than once a year $(3.7 \pm 0.5)$ " scored very highly. In contrast, "counting the patient's total number of teeth $(3.0 \pm 0.8)$ ", "checking the one's inside of mouth with a mirror by oneself ( $3.3 \pm 0.6)$ ", "biting firmly on molar or dentures $(3.3 \pm 0.6)$ ", and "toothbrushing one by one very carefully (3.3 \pm 0.6$)$ ", showed lower scores compared with the others.

The average total implementation score was $1.5 \pm 0.5$ points out of a possible 4 . Those items with very low scores were as follows: "counting the patient's total number of teeth (1.2 \pm 0.5$)$ ", "biting firmly on molar or dentures $(1.3 \pm 0.6)$ ", "toothbrushing around the border between the teeth and marginal gingiva $(1.3 \pm 0.6)$ ", "checking the one's inside of mouth with a mirror by oneself $(1.3 \pm 0.6)$ ", and "toothbrushing one by one very carefully $(1.3 \pm 0.7)$ ". In contrast, those items showing higher scores were as follows: "dentures $(2.3 \pm 1.1)$ ", "knowledge of a relationship between periodontal disease and systemic disease including diabetes $(2.0 \pm 1.0)$ "; "dental visiting more than once a year $(1.9 \pm 1.0)$ "; and "showing diabetes information-sharing notebook to the dentist $(1.7 \pm 1.0)$ ".

In the comparison between recognition scores and implementation scores, the latter were significantly lower for all factors $(p<0.001)$. Furthermore, for all items of the implementation scores were very low $(p<0.001)$.

\section{Discussion}

For all assessment items, Cronbach's alpha coefficient of reliability was 0.932 , with the $\alpha$-coefficients of the four factors ranked below ranging from 0.793 to 0.890 , suggesting a rather high level of reliability of the items. The assessment items were confirmed to be reliable from a statistical point of view. In addition, it was considered clinical validity of the DiOHAT@ is likely to be sufficient, because its items were developed based on agree- 
Table 2. Result of factor analysis for assessment items for nurses (Row of factors after rotation).

Assessment Items

Factor 1: Patient's oral health status $(\alpha=0.874)$

Bleeding during toothbrushing

Abscess on gingiva

Awareness of halitosis

Dentures (partial or full)

Biting firmly on molar or dentures

Checking the patient's inside of mouth

Counting the patient's total number of teeth (dentures, bridges and implants are excluded)

Factor 2: Patient's implementation of oral health behaviors $(\alpha=0.890)$

Toothbrushing around the border between the teeth and marginal gingiva

Toothbrushing one by one very carefully

Supplementary tools

(e.g., interdental brush, dental floss.)

Checking the one's inside of mouth (teeth, gums, buccal mucosa, and tongues)

with a mirror by oneself

Experience being given dentists’ instructions for brushing

Dental visiting more than once a year

Factor 1

Factor 2

Factor 3

Factor 4

Factor 3: Patient's information

transmission regarding dental visits $(\alpha=\mathbf{0 . 8 6 2})$

Showing medicine information-sharing

notebook to the dentist

Showing diabetes information-sharing

notebook to the dentist

Showing self-monitoring blood glucose

notebook to the dentist

Telling dental treatment to the diabetes

doctor

Telling dental treatment to the diabetes nurse

Factor 4: Patient's perceptions and knowledge

of oral health behaviors $(\alpha=0.793)$

Perceptions of one's oral health status

Perceptions of oral care efficacy regardless of timing of care initiation

Knowledge of a relationship between

periodontal disease and systemic

disease including diabetes

\begin{tabular}{|l|lll}
\hline 0.706 & 0.309 & 0.183 & 0.184 \\
0.697 & 0.315 & 0.238 & 0.175 \\
0.670 & 0.351 & 0.183 & 0.128 \\
0.633 & 0.134 & 0.081 & 0.283 \\
0.603 & 0.237 & 0.239 & 0.188 \\
0.555 & 0.263 & 0.073 & 0.255 \\
0.446 & 0.136 & 0.104 & 0.135
\end{tabular}

0.302

0.853
0.815
0.762
0.583
0.400
0.333

0.160

0.230

0.284

0.173

0.224

0.346

0.385

0.366

0.169

0.152

0.095

0.221

0.178

0.143

0.270

0.090

0.100

0.761
0.745
0.728
0.685
0.595

0.089

$0.110 \quad 0.107$

0.069

0.079

0.186

0.124

0.241

0.154

0.190

0.354

0.142

0.240

\begin{tabular}{|lll|l|}
0.362 & 0.245 & 0.212 & 0.717 \\
0.300 & 0.271 & 0.239 & 0.578 \\
0.334 & 0.158 & 0.195 & 0.545 \\
\hline
\end{tabular}

\begin{tabular}{|c|c|c|c|c|c|}
\hline \multirow{2}{*}{$\begin{array}{c}\text { Square sum of loading after } \\
\text { rotation }\end{array}$} & Fixed value & 3.847 & 3.321 & 3.168 & 1.769 \\
\hline & Cumulative rate (\%) & 18.321 & 34.133 & 49.217 & 57.640 \\
\hline \multirow{4}{*}{$\begin{array}{l}\text { Correlation factor between } \\
\text { contents: significance } \\
\text { probability (one sided test) } \\
\text { Spearman }\end{array}$} & Factor 1 & 1.000 & & & \\
\hline & Factor 2 & 0.692 & 1.000 & & \\
\hline & Factor 3 & 0.468 & 0.541 & 1.000 & \\
\hline & Factor 4 & 0.626 & 0.589 & 0.488 & 1.000 \\
\hline
\end{tabular}

Method to select factors: Primary factor method. Barimax rotation method supplemented by a normalization of Kaiser rotation method. Cronbach's alpha coefficient $(\alpha) 0.932$ for all assessment items. 
Table 3. Comparison between recognitions and implementation of nursing specialists.

\begin{tabular}{|c|c|c|c|c|c|c|}
\hline \multirow{2}{*}{ Assessment Items } & \multicolumn{2}{|c|}{ Recognition } & \multicolumn{2}{|c|}{ Implementation } & \multirow{2}{*}{$t$ value $^{1)}$} & \multirow{2}{*}{$p$ value $^{2}$} \\
\hline & Mean & SD & Mean & SD & & \\
\hline Total score & 3.5 & 0.4 & 1.5 & 0.5 & 54.4 & *** \\
\hline Factor 1: Patient's oral health status & 3.4 & 0.5 & 1.5 & 0.5 & 51.4 & ** \\
\hline Bleeding during toothbrushing & 3.5 & 0.6 & 1.5 & 0.7 & 42.8 & $* *$ \\
\hline Abscess on gingiva & 3.4 & 0.6 & 1.4 & 0.7 & 42.6 & *** \\
\hline Awareness of halitosis & 3.3 & 0.7 & 1.4 & 0.7 & 40.8 & ** \\
\hline Dentures (partial or full) & 3.6 & 0.5 & 2.3 & 1.1 & 20.6 & ** \\
\hline Biting firmly on molar or dentures & 3.3 & 0.6 & 1.3 & 0.6 & 44.8 & ** \\
\hline Checking the patient's inside of mouth & 3.6 & 0.6 & 1.6 & 0.8 & 41.1 & ** \\
\hline $\begin{array}{l}\text { Counting the patient's total number of teeth } \\
\text { (dentures, bridges and implants are excluded) }\end{array}$ & 3.0 & 0.8 & 1.2 & 0.5 & 40.4 & $* *$ \\
\hline Factor 2: Patient's implementation of oral health behaviors & 3.4 & 0.5 & 1.5 & 0.6 & 48.0 & ** \\
\hline Toothbrushing around the border between the teeth and marginal gingiva & 3.4 & 0.6 & 1.3 & 0.6 & 44.2 & ** \\
\hline Toothbrushing one by one very carefully & 3.3 & 0.6 & 1.3 & 0.7 & 43.0 & ** \\
\hline Supplementary tools (e.g., interdental brush, dental floss) & 3.3 & 0.7 & 1.4 & 0.7 & 39.0 & ** \\
\hline $\begin{array}{l}\text { Checking the one's inside of mouth } \\
\text { (teeth, gums, buccal mucosa, and tongues) with a mirror by oneself }\end{array}$ & 3.3 & 0.6 & 1.3 & 0.6 & 45.0 & $* *$ \\
\hline Experience being given dentists’ instructions for brushing & 3.4 & 0.6 & 1.5 & 0.8 & 37.4 & ** \\
\hline Dental visiting more than once a year & 3.7 & 0.5 & 1.9 & 1.0 & 31.1 & ** \\
\hline Factor 3: Patient's information transmission regarding dental visits & 3.5 & 0.5 & 1.6 & 0.7 & 42.5 & ** \\
\hline Showing medicine information-sharing notebook to the dentist & 3.5 & 0.6 & 1.6 & 0.9 & 36.0 & ** \\
\hline Showing diabetes information-sharing notebook to the dentist & 3.6 & 0.6 & 1.7 & 1.0 & 34.9 & ** \\
\hline Showing self-monitoring blood glucose notebook to the dentist & 3.3 & 0.7 & 1.5 & 0.8 & 35.8 & ** \\
\hline Telling dental treatment to the diabetes doctor & 3.6 & 0.6 & 1.7 & 0.9 & 34.1 & $* *$ \\
\hline Telling dental treatment to the diabetes nurse & 3.4 & 0.6 & 1.4 & 0.8 & 38.8 & ** \\
\hline $\begin{array}{l}\text { Factor 4: Patient's perceptions and knowledge } \\
\text { of oral health behaviors }\end{array}$ & 3.7 & 0.4 & 1.7 & 0.7 & 44.2 & $* *$ \\
\hline Perceptions of one's oral health status & 3.6 & 0.5 & 1.6 & 0.7 & 43.5 & ** \\
\hline Perceptions of oral care efficacy regardless of timing of care initiation & 3.5 & 0.6 & 1.5 & 0.7 & 42.3 & ** \\
\hline $\begin{array}{l}\text { Knowledge of a relationship between periodontal disease and systemic } \\
\text { disease including diabetes }\end{array}$ & 3.8 & 0.4 & 2.0 & 1.0 & 32.1 & $* *$ \\
\hline
\end{tabular}

${ }^{1)}$ Paired t-test. ${ }^{2)^{* *}}: p<0.001$.

ments among the diabetes health care professionals.

The DNS recognized most of the items to be "necessary". In particular, the following items were also found to be necessary: "knowledge of a relationship between periodontal disease and systemic diseases including diabetes", "dental visiting more than once a year", "perception of one's oral health status", "showing diabetes information-sharing notebook to the dentist", and "telling dental treatment to the diabetes doctor".

It was considered by DNS that communication with dentists is an important, and recognizing the importance of periodontal disease. In addition, for items such as "dentures (full/partial)", "knowledge of a relationship between periodontal disease and systemic disease including diabetes", and "dental visiting more than once a year", almost half of the DNS answered “yes”. However, most of DNS didn’t assess about patient's dental status and 
functions, such as "counting the patient's total number of teeth", “checking the one's inside of mouth with a mirror by oneself", and "biting firmly on molar or dentures". Similarly, the items assessing the actual status of the implementation of oral health behaviors, such as "toothbrushing around the border between the teeth and marginal gingiva" and "toothbrushing one by one very carefully", showed lower scores. This showed that although they understood the basic concept of oral health behaviors, they have not yet confirmed what to do to avoid aggravation of dental status. Therefore oral education for nurses is important and oral assessment items are needed.

Regarding patients' feet, nurses often watch, care, and educate [30] patients to prevent foot ulcers. Similar to the case of foot care, it is easy to obtain information about the oral cavity by direct visual observation with penlight. Nurses' counting the number of teeth [31] is a useful method to assess the health of the oral cavity without any expertise required. It is possible to determine the trajectory of oral illness by the loss of teeth, due to periodontal disease or dental caries, which enables us to acquire important information to evaluate oral functions such as mastication. The loss of teeth reduces mastication ability, alters the senses in the oral cavity, and affects physical appearance. By counting the patients' total number of teeth, nurses can watch the position of the teeth and they can get the data of cleanliness of the oral cavity, too. Then it is possible to estimate the mastication function and implementation of oral health behavior. In addition, it is also reported that "total number of teeth" is linked to dementia [32], mortality [33], and quality of life [34].

Nurses are positively involved in solving problems associated with the oral cavity, as caused by systemic diseases. For example, when patients' suffering from chemotherapy induced oral mucositis [25]-[27], stroke care settings [35], in these patients situation, nurses have to provide oral care for such patients. In the textbooks used in fundamental nursing courses, there are few descriptions on dental mastication, which is a basic oral function, but there are instructions for classic tooth brushing. It is obvious that there is a need to strengthen the basic information on oral health assessment [36], which included occlusion and mastication.

Further discussions from the viewpoint of nursing education are necessary. Nurses need to assess the oral cavity of patients. Self-monitoring [37], (e.g., blood glucose, body weight, diet) is important for the patients. A positive involvement in oral care by nurses might provide good effects through patients' self-care. In addition, oral care by nurses is not appreciated enough in the Japanese medical insurance system; and foot care is rewarded by medical service fees to nurses: this is not the case for oral care. As Costello et al. [38] pointed out, while nurses appreciate the need for oral care, in reality they lack knowledge and experience about this area of care.

In the consideration of the oral health behavior of patients, it is essential to evaluate the number of existing teeth. Based on the results obtained, loss of any teeth increased the importance of the remaining teeth. Nurses need to collect comprehensive data to provide patients with appropriate oral care using evidence-based assessment tools. In checking the patients' oral cavity, the nurses evaluate their oral functions.

The findings of the study further showed that although the DNS recognized the usefulness of the assessment items, they were not inclined to perform them. These warrant further investigation.

\section{Limitations}

In this research study the response rate for returning the questionnaire was $43.4 \%$, this was not satisfactory. In the future, it is necessary to clarify the problems occurring on the clinical sites clearer by utilizing these assessment items of DiOHAT@ as a trial for examining the patients’ oral health status and behaviors.

\section{Conclusion}

The DiOHAT@ was developed with the four factors: Patient's oral health status, Patient's implementation of oral health behaviors, Patient's information transmission regarding dental visits, and Patient's perceptions and knowledge of oral health behaviors. These four factors were determined reliable and valid by factor analysis, and Cronbach's alpha coefficient of reliability of 0.932. However, DNS did not assess all items of oral health behaviors in the DiOHATC despite being aware of the importance of the assessment items.

\section{Acknowledgements}

This work was supported by Japan Society for the Promotion of Science (JSPS), JSPS KAKENHI Grant Num- 
ber 26463305, and Grant-in-Aid for Scientific Research (C). We are grateful to the nurses who participated in this study and we appreciate clinicians: Dr. Hamada Y., MD, Ms. Ishida N., RN, Ms. Takikawa I., RN, Ms. Yamato H., RN, and Ms. Kikui S. helping this study.

\section{Competing Interests}

The authors declare that they have no competing interests for this article.

\section{References}

[1] Ministry of Health, Labour and Welfare. Health Japan 21 (The Second Team): Analysis and Assessment project. Annual Changes in Current Data, Table 2 Targets of the Prevention of Onset and Progression of Life-Style Related Disease: Diabetes.

http://www.mhlw.go.jp/seisakunitsuite/bunya/kenkou_iryou/kenkou/kenkounippon21/en/kenkounippon21/data02.html \#c0

[2] American Diabetes Association: Living with Diabetes. http://www.diabetes.org/living-with-diabetes/

[3] Suzuki, H., Fukushima, M., Okamoto, S., Takahashi, O., Shimbo, T., Kurose, T., Yamada, Y., Inagaki, N., Seino, Y. and Fukui, T. (2005) Effect of Thorough Mastication on Postprandial Plasma Glucose Concentration in Nonobese Japanese Participants. Metabolism Clinical and Experimental, 54, 1593-1599.

http://dx.doi.org/10.1016/j.metabol.2005.06.006

[4] Ranawana, V., Henry, C.J. and Pratt, M. (2010) Degree of Habitual Mastication Seems to Contribute to Interindividual Variations in the Glycemic Response to Rince But Not to Spaghetti. Nutrition Research, 30, 382-391. http://dx.doi.org/10.1016/j.nutres.2010.06.002

[5] Sonoki, K., Iwase, M., Takata, Y., Nakamoto, T., Masaki, C., Hosokawa, R., Murakami, S., Chiwata, K. and Inoue, H. (2013) Effects of Thirty-Times Chewing per Bite on Secretion of Glucagon-Like Peptide-1 in Healthy Volunteers and Type 2 Diabetic Patients. Endocrine Journal, 60, 311-319. http://dx.doi.org/10.1507/endocrj.EJ12-0310

[6] Imai, S., Matsuda, M., Hasegawa, G., Fukui, M., Obayashi, H., Ozasa, N. and Kajiyama S. (2011) A Simple Meal Plan of "Eating Vegetables before Carbohydrate” Was More Effective for Achieving Glycemic Control than an ExchangeBased Meal Plan in Japanese Patients with Type 2 Diabetes. Asia Pacific Journal of Clinical Nutrition, 20, 161-168. http://apjcn.nhri.org.tw/server/APJCN/20/2/161.pdf

[7] Yamazaki, T., Yamori, M., Asai, K., Nakano-Araki, I., Yamaguchi, A., Takahashi, K., Sekine, A., Matsuda, F., Kosugi, S., Nakayama, T., Inagaki, N. and Bessho, K., Nagahama Study Collaboration Group (2013) Mastication and Risk for Diabetes in Japanese Population: A Cross-Sectional Study. PLoS ONE, 8, e64113. http://dx.doi.org/10.1371/journal.pone.0064113

[8] Ministry of Health, Labour and Welfare: Statisticaltables of the Survey of Dental Diseases. (In Japanese with English) http://www.mhlw.go.jp/toukei/list/62-17c.html

[9] Nelson, R.G., Shlossman, M., Budding, L.M., Pettitt, D.J., Saad, M.F., Genco, R.J. And Knowler, W.C. (1990) Periodontal Disease and NIDDM in Pima Indians. Diabetes Care, 13, 836-840. http://dx.doi.org/10.2337/diacare.13.8.836

[10] Seppälä, B., Seppälä, M. and Ainamo, J. (1993) A Longitudinal Study on Insulin-Dependent Diabetes Mellitus and Periodontal Disease. Journal of Clinical Periodontology, 20, 161-165. http://dx.doi.org/10.1111/j.1600-051X.1993.tb00338.x

[11] Löe, H. (1993) Periodontal Disease: The Sixth Complication of Diabetes Mellitus. Diabetes Care, 16, 329-334. http://dx.doi.org/10.2337/diacare.16.1.329

[12] Collin, H.L., Uusitupa, M., Niskanen, L., Kontturi-Närhi, V., Markkanen, H., Koivisto, A.M. and Meurman, J.H. (1998) Periodontal Findings in Elderly Patients with Non-Insulin Dependent Diabetes Mellitus. Journal of Periodontology, 69, 962-966. http://dx.doi.org/10.1902/jop.1998.69.9.962

[13] Choi, Y.H., McKeown, R.E., Mayer-Davis, E.J., Liese, A.D., Song, K.B. and Merchant, A.T. (2011) Association between Periodontitis and Impaired Fasting Glucose and Diabetes. Diabetes Care, 34, 381-386. http://dx.doi.org/10.2337/dc10-1354

[14] Japan Association for Diabetes Education and Care. (In Japanese) http://www.nittokyo.or.jp/patient/goods/handbook.html

[15] Kishimoto, I., Ashida, Y., Omori, Y., Nishi, H., Hagiwara, Y., Fujimoto, T., Makino, H., Ohata, Y., Iwane, M., Iinuma, K., Maeda, K. and Sato, S. (2013) Surveillance and Evaluation of Diabetes Management in the Toyono Medical District. Journal of the Japan Diabetes Society, 56, 543-550. (In Japanese, abstract in English) http://doi.org/10.11213/tonyobyo.56.543

[16] Strauss, S.M., Rosedale, M.T., Pesce, M.A., Rindskopf, D.M., Kaur, N., Juterbock, C.M., Wolff, M.S., Malaspina, D. 
and Danoff, A. (2015) The Potential for Glycemic Control Monitoring and Screening for Diabetes at Dental Visits Using Oral Blood. The American Journal of Public Health, 105, 796-801. http://dx.doi.org/10.2105/AJPH.2014.302357

[17] Kuwamura, Y. and Matsuda, N. (2013) Oral Health Behaviors and Assosiated Factoers in Patients with Diabetes. Bulletin of Health Sciences in Kobe, 29, 1-16. http://www.lib.kobe-u.ac.jp/handle_kernel/81005509

[18] Broadbent, E., Donkin, L. and Stroh, J.C. (2011) Illness and Treatment Perceptions Are Associated with Adherence to Medications, Diet, and Exercise in Diabetic Patients. Diabetes Care, 34, 338-340. http://dx.doi.org/10.2337/dc10-1779

[19] Redman, B.K. (2004) Chapter 2: Advances in Learning Theory for Patient Education. Springer Publishing Company, New York, 17-37.

[20] Saremi, A., Nelson, R.G., Tulloch-Reid, M., Hanson, R.L., Sievers, M.L., Taylor, G.W., Shlossman, M., Bennett, P.H., Genco, R. and Knowler, W.C. (2005) Periodontal Disease and Mortality in Type 2 Diabetes. Diabetes Care, 28, $27-32$. http://dx.doi.org/10.2337/diacare.28.1.27

[21] Eilers, J., Berger, A.M. and Petersen, M.C. (1988) Development, Testing, and Application of the Oral Assessment Guide. Oncology Nursing Forum, 15, 325-330.

[22] Andersson, P., Hallberg, I.R. and Renvert, S. (2002) Inter-Rater Reliability of an Oral Assessment Guide for Elderly Patients Residing in a Rehabilitation Ward. Special Care in Dentistry, 22, 181-186. http://dx.doi.org/10.1111/j.1754-4505.2002.tb00268.x

[23] Ribeiro, M.T., Ferreira, R.C., Vargas, A.M. and e Ferreira, E.F. (2014) Validity and Reproducibility of the Revised Oral Assessment Guide Applied by Community Health Workers. Gerodontology, 31, 101-110. http://dx.doi.org/10.1111/ger.12014

[24] Sjögren, R. and Nordström, G. (2000) Oral Health Status of Psychiatric Patients. Journal of Clinical Nursing, 9, 632638. http://dx.doi.org/10.1046/j.1365-2702.2000.00380.x

[25] Miller, M., Taylor, A., Kearney, N., Paterson, G., Wells, M., Roe, L., Hagen, S. and Maguire, R. (2007) Evaluation of the Feasibility and Acceptability of an Oral Care Diary by Patients during Chemotherapy. International Journal of Nursing Studies, 44, 693-701. http://dx.doi.org/10.1016/j.ijnurstu.2006.01.009

[26] Berger, A.M. and Eilers, J. (1998) Factors Influencing Oral Cavity Status during High-Dose Antineoplastic Therapy: A Secondary Data Analysis. Oncology Nursing Forum, 25, 1623-1629.

[27] Chen, C.F., Wang, R.H., Cheng, S.N. and Chang, Y.C. (2004) Assessment of Chemotherapy-Induced Oral Complications in Children with Cancer. Journal of Pediatric oncology Nursing, 21, 33-39. http://dx.doi.org/10.1177/1043454203259947

[28] Knöös, M. and Ostman, M. (2010) Oral Assessment Guide-Test of Reliability and Validity for Patients Receiving Radiotherapy to the Head and Neck Region. European Journal of Cancer Care, 19, 53-60. http://dx.doi.org/10.1111/j.1365-2354.2008.00958.x

[29] Markuson, M., Hanson, D., Anderson, J., Langemo, D., Hunter, S., Thompson, P., Paulson, R. and Rustvang, D. (2009) The Relationship between Hemoglobin A1c Values and Healing Time for Lower Extremity Ulcers in Individuals with Diabetes. Advances in Skin \& Wound Care, 22, 365-372. http://dx.doi.org/10.1097/01.ASW.0000358639.45784.cd

[30] Nemcová, J. and Hlinková, E. (2014) The Efficacy of Diabetic Foot Care Education. Journal of Clinical Nursing, 23, 877-882. http://dx.doi.org/10.1111/jocn.12290

[31] Warren, J.J., Levy, S.M. and Hand, J.S. (1999) The Accuracy of Tooth Loss Data Collected by Nurses. Special Care in Dentistry, 19, 75-78. http://dx.doi.org/10.1111/j.1754-4505.1999.tb01372.x

[32] Luo, J., Wu, B., Zhao, Q., Guo, Q., Meng, H., Yu, L., Zheng, L., Hong, Z. and Ding, D. (2015) Association between Tooth Loss and Cognitive Function among 3063 Chinese Older Adults: A Community-Based Study. PLoS ONE, 10, e0120986. http://dx.doi.org/10.1371/journal.pone.0120986

[33] Liljestrand, J.M., Havulinna, A.S., Paju, S., Männistö, S., Salomaa, V. and Pussinen, P.J. (2015) Missing Teeth Predict Incident Cardiovascular Events, Diabetes, and Death. Journal of Dental Research, 94, 1055-1062. http://dx.doi.org/10.1177/0022034515586352

[34] Huang, D.L., Chan, K.C. and Young, B.A. (2013) Poor Oral Health and Quality of Life in Older U.S. Adults with Diabetes Mellitus. Journal of the American Geriatrics Society, 61, 1782-1788. http://dx.doi.org/10.1111/jgs.12452

[35] Brady, M.C., Stott, D., Weir, C.J., Chalmers, C., Sweeney, P., Donaldson, C., Barr, J., Barr, M., Pollock, A., McGowan, S., Bowers, N. and Langhorne, P. (2015) Clinical and Cost Effectiveness of Enhanced Oral Healthcare in Stroke Care Settings (SOCLE II): A Pilot, Stepped Wedge, Cluster Randomized, Controlled Trial Protocol. International Journal of Stroke, 10, 979-984. http://dx.doi.org/10.1111/ijs.12530

[36] Munoz, N., Touger-Decker, R., Byham-Gray, L. and Maillet, J.O. (2009) Effect of an Oral Health Assessment Education Program on Nurses’ Knowledge and Patient Care Practices in Skilled Nursing Facilities. Special Care in Dentistry, 
29, 179-185. http://dx.doi.org/10.1111/j.1754-4505.2009.00084.x

[37] Wing, R.R., Hamman, R.F., Bray, G.A., Delahanty, L., Edelstein, S.L., Hill, J.O., Horton, E.S., Hoskin, M.A., Kriska, A., Lachin, J., Mayer-Davis, E.J., Pi-Sunyer, X., Regensteiner, J.G., Venditti, B. and Wylie-Rosett, J. (2004) Achieving Weight and Activity Goals among Diabetes Prevention Program Lifestyle Participants. Obesity Research, 12, 1426-1434. http://dx.doi.org/10.1038/oby.2004.179

[38] Costello, T. and Coyne, I. (2008) Nurses’ Knowledge of Mouth Care Practices. British Journal of Nursing, 17, $264-268$. http://dx.doi.org/10.12968/bjon.2008.17.4.28716 